\title{
Onset of Dementia Is Associated with Age at Menopause in Women with Down's Syndrome
}

\author{
Nicole Schupf, PhD, ${ }^{1-3}$ Deborah Pang, $\mathrm{MPH},{ }^{2}$ Bindu N. Patel, MPH, ${ }^{2}$ Wayne Silverman, PhD, ${ }^{2}$ \\ Romaine Schubert, MD, ${ }^{2}$ Florence Lai, MD, ${ }^{4}$ Jennie K. Kline, PhD, ${ }^{3,5,6}$ Yaakov Stern, PhD, ${ }^{1,3}$ \\ Michel Ferin, MD, ${ }^{7}$ Benjamin Tycko, MD, PhD, ${ }^{1,8}$ and Richard Mayeux, MD, MSE ${ }^{1,3,9}$
}

\begin{abstract}
Women with Down's syndrome experience early onset of both menopause and Alzheimer's disease. This timing provides an opportunity to examine the influence of endogenous estrogen deficiency, indicated by age at menopause, on risk of Alzheimer's disease. A community-based sample of 163 postmenopausal women with Down's syndrome, 40 to 60 years of age, was ascertained through the New York State Developmental Disability service system. Information from cognitive assessments, medical record review, neurological evaluation, and caregiver interviews was used to establish ages for onset of menopause and dementia. We used survival and multivariate regression analyses to determine the relation of age at menopause to age at onset of Alzheimer's disease, adjusting for age, level of mental retardation, body mass index, and history of hypothyroidism or depression. Women with early onset of menopause (46 years or younger) had earlier onset and increased risk of Alzheimer's disease $(\mathrm{AD})$ compared with women with onset of menopause after 46 years (rate ratio, 2.7; 95\% confidence interval $[\mathrm{CI}], 1.2-5.9)$. Demented women had higher mean serum sex hormone binding globulin levels than nondemented women $(86.4 \mathrm{vs} 56.6 \mathrm{nmol} / \mathrm{L}, p=0.02)$, but similar levels of total estradiol, suggesting that bioavailable estradiol, rather than total estradiol, is associated with dementia. Our findings support the hypothesis that reductions in estrogens after menopause contribute to the cascade of pathological processes leading to AD.
\end{abstract}

Ann Neurol 2003;54:433-438

Several lines of evidence suggest that the loss of estrogen in the perimenopausal period and after menopause may play a role in the cognitive declines associated with $\mathrm{AD}$. Before menopause, estrogen promotes the growth and survival of cholinergic neurons, ${ }^{1,2}$ increases cholinergic activity, ${ }^{3}$ has antioxidant properties, ${ }^{4}$ and promotes the nonamyloidogenic metabolism of the amyloid precursor protein. ${ }^{5-7}$ In an animal model, ovariectomy led to increased levels of amyloid beta peptides $A \beta 1-40$ and $A \beta 1-42$ in the brain, and this effect was partially reversible with exogenous estrogen treatment. ${ }^{8,9}$ In some, but not all, observational studies, postmenopausal women who used estrogen replacement therapy (ERT) showed slower declines in cognitive function and decreased risk of $\mathrm{AD}$ compared with women who never used ERT. ${ }^{10-20}$ Alternatively, ERT use may be associated with protective factors such as higher educational levels and better access to medical care, ${ }^{21}$ and these, rather than ERT use per se, may be the factors that caused these effects. Studies of endogenous estrogen are important to distinguish between these alternatives and to understand the role of estrogen in the pathogenesis of AD. Only a few studies have examined the relationship of endogenous estrogen levels to cognitive decline in healthy women or to risk of $A D$, and the results have been inconsistent. ${ }^{22-27}$

The relationship between menopause and $\mathrm{AD}$ is difficult to study in the general population because of the extended time period that elapses between menopause, which typically occurs at 51 years of age, ${ }^{28,29}$ and onset of $\mathrm{AD}$, which typically occurs after age 70 years. In contrast, adults with Down's syndrome (DS) have a much earlier onset of $\mathrm{AD}$. Virtually all subjects with $\mathrm{DS}$ have the neuropathological changes characteristic of $\mathrm{AD}$,
From the ${ }^{1}$ The Taub Institute for Research on Alzheimer's Disease and the Aging Brain, Columbia University, New York; ${ }^{2}$ New York State Institute for Basic Research in Developmental Disabilities, Staten Island; ${ }^{3}$ The Gertrude H. Sergievsky Center, Columbia University, New York, NY; ${ }^{4}$ Departments of Neurology, Massachusetts General Hospital and McLean Hospital, Belmont, MA; ${ }^{5}$ Department of Epidemiology in the Mailman School of Public Health, Columbia University; ${ }^{6}$ Epidemiology of Developmental Brain Disorders, New York State Psychiatric Institute, New York; and Departments of ${ }^{7}$ Obstetrics and Gynecology, ${ }^{8}$ Pathology, and ${ }^{9}$ Neurology and Psychiatry, Columbia University, New York, NY.
Received Jul 12, 2002, and in revised form Jan 13, 2003. Accepted for publication May 21, 2003.

Address correspondence to Dr Schupf, The Taub Institute for Research on Alzheimer's Disease and the Aging Brain, College of Physicians and Surgeons, P.O. Box 16, 630 West 168th Street, New York, NY 10032. E-mail: ns24@columbia.edu 
including deposition of $\beta$-amyloid in diffuse and neuritic plaques, by age 35 years. ${ }^{30}$ The increased risk of $\mathrm{AD}$ neuropathology in DS may be caused, at least in part, by triplication and overexpression of the gene for amyloid precursor protein, located on chromosome 21, leading to the accumulation of cerebral $\beta$-amyloid. ${ }^{31,32}$ Women with DS also experience early menopause and have an increased risk for $\mathrm{AD}$ onset beginning in their late 40 s and early 50 s. $^{33,34}$ Thus, many women with DS experience onset of $\mathrm{AD}$ more closely in time to their onset of menopause than is typical in the general population. This timing provides an opportunity to examine the influence of endogenous estrogen deficiency, indicated by age at menopause, on risk of $\mathrm{AD}$.

One previous study found a correlation between age at menopause and onset of $\mathrm{AD}$ in women with $\mathrm{DS}, 35$ but the number of dementia cases was low and supporting hormonal data were not available. In addition, the presence of the apolipoprotein $\mathrm{E}$ (ApoE) $\varepsilon 4$ allele is associated with earlier age at onset and increased risk of $\mathrm{AD}$ in adults with and without DS. ${ }^{36-38}$ Therefore, the relation between age at menopause and onset of $\mathrm{AD}$ might be stronger in women with the $\varepsilon 4$ allele. This study was designed to examine the relation of age at menopause to age at onset of $\mathrm{AD}$, to determine whether this association is modified by the presence of the ApoE $\varepsilon 4$ allele, and to determine the relation of hormone levels to dementia status. We hypothesized that earlier onset of menopause would be associated with earlier onset of $\mathrm{AD}$.

\section{Subjects and Methods}

\section{Subjects}

A community-based sample of 163 postmenopausal women with cytogenetically confirmed DS, 40 to 60 years of age, and residing in New York State was ascertained from the statewide service system and recruited with the help of state and voluntary service provider agencies. Subjects were eligible to participate in the study if they had a family member or correspondent who could provide informed consent. Informed consent was signed by a parent or correspondent, and subjects also signed a form acknowledging their willingness to participate. The participation rate was $74.6 \%$. Recruitment, informed consent, and study procedures were approved by the institutional review boards of the New York State Institute for Basic Research in Developmental Disabilities and Columbia Presbyterian Medical Center and Columbia University Health Sciences.

\section{Clinical Assessment}

Clinical assessments included evaluation of cognition and functional abilities, and ascertainment of psychiatric conditions and health status. Assessments were repeated at 14 to 18-month intervals for two to three cycles of data collection to document declines over time. Cognitive status was evaluated with a test battery used to assess cognitive functions that are typically affected in $\mathrm{AD}$, using standardized instruments for detecting dementia in adults with mental retardation. The cognitive assessment battery consisted of the Down Syndrome Mental Status Exam, ${ }^{39}$ the IBR Mental Status
Exam, ${ }^{40}$ a modified Selective Reminding Test, ${ }^{41}$ the Peabody Picture Vocabulary test, ${ }^{42}$ Verbal Fluency Test, ${ }^{43}$ VisualMotor Integration test, ${ }^{44}$ the WISC-R Block Design, ${ }^{45}$ and the Test for Severe Impairment. ${ }^{46}$ Adaptive and maladaptive behaviors were assessed in caregiver interviews using the AAMR Adaptive Behavior Scale., ${ }^{47}$ the Dementia Rating Scale for Mentally Retarded Persons, ${ }^{48}$ and the Reiss Screen for Maladaptive Behavior. ${ }^{49}$ Past and current medical records were reviewed for all participants. Structured interviews were conducted with caregivers to collect information on changes in cognitive function, adaptive behavior, and medical history. Participants showing declines in cognition or in adaptive behavior were evaluated by the study neurologist to determine the presence of dementia and determine the presence or absence of medical or psychiatric conditions other than $\mathrm{AD}$ that might result in or mimic dementia. These procedures were consistent with recommendations developed by the Working Group for the Establishment of Criteria for the Diagnosis of Dementia in Individuals with Intellectual Disability. ${ }^{50}$

\section{Classification of Age at Menopause}

Age at menopause was ascertained by medical record review, interviews with caregivers and family members, and survey of the participants' primary care physicians and gynecologists. The medical records included menstrual charts documenting the date and duration of menses. The correlations between age at menopause ascertained from the different sources were substantial, suggesting that ascertainment of age at menopause was reliable. The correlation between age at menopause ascertained from medical records, including menstrual charts, and from physician survey was 0.99 ; the correlation between age at menopause ascertained from medical records and from informant interviews was 0.77; and the correlation between age at menopause ascertained from physician survey and from informant interview was 0.80 . The mean difference in age at menopause from the different sources ranged from 0.21 years $( \pm 2.8)$ for the difference between age at menopause ascertained from medical chart and from physician survey to 0.38 years $( \pm 2.9)$ for the difference between age at menopause ascertained from medical charts and from informant interview. We used a consensus age at menopause, with greater weight given to age at menopause ascertained from medical records, then physician survey, then informant interviews. In keeping with convention, we classified age at natural menopause as the age at the last menstrual period preceding cessation of menses for 12 months, in the absence of known causes of amenorrhea (eg, surgery). The median age at menopause was 46.0 years (range, 35-52). For analysis of $\mathrm{AD}$ risk associated with age at menopause, we split at the median to classify women as experiencing "early" ( $\leq 46$ years) or "late" (>46 years) age at menopause. Sixteen women had menopause at age 46 years, and they were all included in the "early" menopause group. Ascertainment of age at menopause was done blind to dementia status, and any misclassification of age at menopause is likely to have been nondifferential for dementia status.

\section{Classification of Alzheimer's Disease}

Classification of $\mathrm{AD}$ was made in consensus conferences during which the presence or absence of dementia was determined and a cause of dementia was assigned. To ascertain the occurrence of $\mathrm{AD}$, we reviewed information from all available sources, includ- 
ing cognitive test scores, medical history, neurological evaluation, and informant-based interviews. We used International Classification of Diseases-10 criteria for dementia. ${ }^{51}$

We classified participants into three groups. (1) Participants were classified as demented if there was a history of progressive memory loss, disorientation, and functional decline over a period of at least 1 year, if no other medical or psychiatric conditions that might result in or mimic dementia were present (eg, untreated hypothyroidism), and if a clinical diagnosis of $\mathrm{AD}$ had been made by a neurologist or psychiatrist familiar with this population $(\mathrm{n}=33)$. To be classified as demented, participants had to meet criteria for dementia based on the cognitive assessment. These included a decline of at least $20 \%$ on the Selective Reminding Test, a decline of at least $15 \%$ on the Adaptive Behavior Scale, and evidence of decline in one other area of cognition. (2) Participants were classified as nondemented if they were without cognitive or functional decline and without a clinical diagnosis $(\mathrm{n}=104)$. (3) Participants were classified as uncertain if they showed some cognitive or functional decline but had no clinical diagnosis or caregiver concern; if there was caregiver concern about decline in function but only small declines in cognitive test performance or adaptive abilities $(n=18)$ or if they had other conditions that might cause dementia (ie, untreated hypothyroidism, brain tumor, schizophrenia, stroke, depression/anxiety, $\mathrm{n}=8$ ). Age at clinical diagnosis was used to estimate age at onset of $\mathrm{AD}$, recognizing that it is difficult to document the onset of initial symptoms in this population with precision. However, this is unlikely to influence our findings systematically because classification of AD was made without knowledge of age at menopause or hormone levels.

\section{Apolipoprotein E Genotypes}

ApoE genotyping was conducted as described in a previous study. ${ }^{37}$ A $10 \mathrm{ml}$ sample of whole blood was collected in an EDTA lavender-top tube. ApoE genotype was determined by a standard polymerase chain reaction restriction fragment length polymorphism method using Hhal ( $C f o \mathrm{I})$ digestion of an ApoE genomic polymerase chain reaction product spanning the polymorphic (cys/arg) sites at codons 112 and 158 . Acrylamide gel electrophoresis was used to assess and document the restriction fragment sizes. Women were classified according to the presence or absence of an ApoE $\varepsilon 4$ allele.

\section{Serum Hormone Levels}

All laboratory studies were conducted without knowledge of age at menopause or dementia status. Blood samples were collected between 10:00 AM and 3:00 PM. Blood was centrifuged in a refrigerated centrifuge and, after separation, sera were frozen at $-20^{\circ} \mathrm{C}$ until assay. Total estradiol and estrone (free + bound) were measured by a no-extraction solid-phase ${ }^{125}$ I-radioimmunoassay using commercial kits (Diagnostic Systems Laboratories, Webster, TX). Sensitivity or minimum detection level for estradiol was $4 \mathrm{pg} / \mathrm{ml}$, and intraassay and interassay coefficients of variation were 3.8 and $15.2 \%$, respectively. Sensitivity or minimum detection level for estrone was $11 \mathrm{pg} / \mathrm{ml}$, and intraassay and interassay coefficients of variation were $6.3 \%$ and $15.8 \%$, respectively. Human follicle-stimulating hormone (FSH), progesterone, dehydroepiandrosterone sulfate (DHEAS), and sex-hormone binding globulin (SHBG) were measured by immunometric assays using Immulite systems (Diagnostic Products Corporation,
Los Angeles, CA). We used two commercial controls for the SHBG assays, the first with a mean level of $4.8 \mathrm{nmol} / \mathrm{L}$ and the second with a mean level of $82 \mathrm{nmol} / \mathrm{L}$. Sensitivity was $0.1 \mathrm{mIU} / \mathrm{ml}$ for FSH, $0.2 \mathrm{ng} / \mathrm{ml}$ for progesterone, $30 \mu \mathrm{g} / \mathrm{dl}$ for DHEAS, and $0.2 \mathrm{nmol} / \mathrm{L}$ for SHBG. Intraassay and interassay coefficients of variation were 6.4 and $7.5 \%$, respectively, for FSH, 8.0 and $9.3 \%$ for progesterone, 8.2 and $12 \%$ for DHEAS, and 6.4 and $8.7 \%$ for SHBG.

\section{Potential Confounders}

Potential confounders, in addition to age, were level of mental retardation, body mass index (BMI), and past or current hypothyroidism or depression. Level of mental retardation was classified into two groups: mild/moderate (IQ 35-70) and severe/profound (IQ <34), based on IQ scores obtained before onset of dementia. Nutritional status and BMI have been associated with increased serum estradiol and estrone levels in postmenopausal women ${ }^{52,53}$ BMI was computed as weight in kilograms divided by height in square meters $\left(\mathrm{kg} / \mathrm{m}^{2}\right)$ and was measured at each assessment. The history of past or current of hypothyroidism and depression was ascertained by medical record review. All women with a history of hypothyroidism were being treated with synthroid.

\section{Statistical Analyses}

We excluded from the analysis women who had never menstruated $(\mathrm{n}=3)$, women with other causes of dementia $(\mathrm{n}=8)$, those with uncertain dementia classification (ie, with signs or symptoms of cognitive decline consistent with mild cognitive impairment: $\mathrm{n}=18$ ), and those for whom we were unable to obtain age at menopause $(n=23)$. The final sample comprised 81 nondemented postmenopausal women and 30 demented postmenopausal women. Blood samples for hormone analyses were available for 93 women (84\%), and ApoE genotypes were available for 96 women (86\%). Among women without a blood sample, $66 \%$ were missing a blood sample for both hormone assays and ApoE genotyping. Women with and without a blood sample did not differ in age or BMI (mean age 50.9 vs 50.7 years, respectively, and mean BMI 28.8 vs 29.0, respectively), but the proportion of women with severe mental retardation was higher among those without a blood sample than among those with a blood sample (65 vs $45 \%$; $p=0.03$ ). We used Student's $t$ test for continuous variables and $\chi^{2}$ tests for categorical variables to compare characteristics of demented and nondemented women. We used Kaplan-Meier life table methods and Cox proportional hazards models, adjusted for age, level of mental retardation, BMI, hypothyroidism, and depression to estimate cumulative incidence of $\mathrm{AD}$ and the rate ratio (RR) for $\mathrm{AD}$ in women with early versus late onset of menopause. ${ }^{54}$ These analyses were repeated in strata defined by the presence or absence of an ApoE $\varepsilon 4$ allele. Multivariate analysis of covariance was used to compare the six measures of hormone levels by dementia status, adjusting for age, level of mental retardation, and BMI. Partial correlations and linear regression analysis were used to estimate the relation of age at menopause with age at onset of $\mathrm{AD}$ among demented women, adjusting for level of mental retardation. All analyses were conducted using SPSS version 11. ${ }^{55}$ 


\section{Results}

Women with dementia did not differ significantly from women without dementia in age, level of mental retardation, BMI, or history of depression. The frequency of the ApoE $\varepsilon 4$ allele was twice as high in demented as in nondemented women $(33.3 \%$ vs $15.3 \%, p=.055)$ (Table 1) and demented women were significantly more likely to have a history of hypothyroidism than nondemented women (73.3 vs $48.1 \%, p=0.01$; Table 1 ). The mean age at menopause was similar in those with and without an ApoE $\varepsilon 4$ allele (44.8 vs 45.5, respectively) and in those with and without a history of hypothyroidism ( 45.5 vs 45.3 , respectively). The mean age at onset of $\mathrm{AD}$ was $50.9( \pm 3.2)$ years, with an average interval between age at menopause and clinical diagnosis of $\mathrm{AD}$ of $5.3( \pm 3.2)$ years. Women with early onset of menopause ( $\leq 46$ years) had earlier onset of dementia compared with women with onset of menopause after 46 years (RR, 2.7; 95\% CI, 1.2-5.9, Table 2, Fig 1). The median age at onset of dementia was 49.5 and 53.5 years in women with early and late onset of menopause, respectively. The presence of an ApoE $\varepsilon 4$ allele was associated with earlier onset and increased risk for $\mathrm{AD}$ (RR, 3.0; 95\% CI, 1.2-7.1). However, the relation between age at menopause and onset of $\mathrm{AD}$ was similar in those with and without an $\varepsilon 4$ allele (RR, 3.1; 95\% CI, $0.6-17.6$ in those with an $\varepsilon 4$ allele and $\mathrm{RR}=2.9 ; 95 \%$ CI, 1.0-8.6 in those without an $\varepsilon 4$ allele). A history of hypothyroidism was also associated with increased risk for dementia (RR, 2.6; 95\% CI, 1.1-6.3), but, as for ApoE, the relation between age at menopause and onset of $\mathrm{AD}$ was similar in those with and without a history of

Table 1. Demographic Characteristics

\begin{tabular}{|c|c|c|}
\hline Characteristic & Nondemented & Demented \\
\hline No. of participants & 81 & 30 \\
\hline Age $($ mean $\pm S D)$ & $49.8(3.9)$ & $51.8(3.0)$ \\
\hline \multicolumn{3}{|l|}{$\begin{array}{l}\text { Level of mental retardation } \\
\qquad(\mathrm{n}, \%)\end{array}$} \\
\hline Mild/moderate & $39(48.1)$ & $18(60.0$ \\
\hline Severe/profound & $42(51.9)$ & $12(40.0)$ \\
\hline $\begin{array}{l}\text { Body mass index (mean } \pm \\
\text { SD) }\end{array}$ & $28.4(6.9)$ & $27.6(5.5)$ \\
\hline \multicolumn{3}{|l|}{$\begin{array}{l}\text { Apolipoprotein E } \varepsilon 4 \text { allele } \\
(\mathrm{n}, \%)\end{array}$} \\
\hline None & $61(84.7)$ & $16(66.7)$ \\
\hline$\geq 1$ & $11(15.3)$ & $8(33.3)^{\mathrm{a}}$ \\
\hline \multicolumn{3}{|l|}{$\begin{array}{l}\text { History of hypothyroidism } \\
\text { (n, \%) }\end{array}$} \\
\hline No & $41(51.2)$ & $7(26.7)$ \\
\hline Yes & $39(48.8)$ & $22(73.3)^{b}$ \\
\hline \multicolumn{3}{|l|}{ History of depression (n, \%) } \\
\hline No & $73(90.1)$ & $26(86.7)$ \\
\hline Yes & $8(9.9)$ & $4(13.3)$ \\
\hline
\end{tabular}

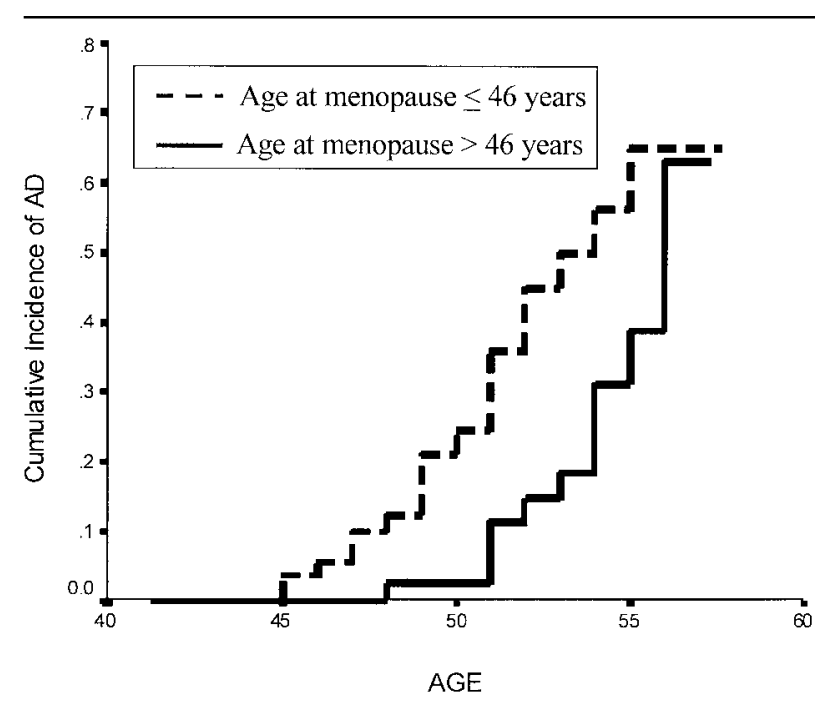

Fig 1. Cumulative incidence of Alzheimer's disease (AD) by age at menopause group in women with Down's syndrome.

hypothyroidism (RR, 3.2; 95\% CI, 1.2-8.6, and RR, $2.995 \%$ CI, 0.5-17.1, respectively).

Mean serum levels of estradiol, estrone, progesterone, FSH, and DHEAS, adjusted for age, level of mental retardation, and BMI did not differ significantly in demented and nondemented women (Table 3). Women with dementia had a $52 \%$ increase in mean serum levels of SHBG compared with women without dementia $(86.4 \mathrm{nmol} / \mathrm{L}$ vs $56.6 \mathrm{nmol} / \mathrm{L}, p=0.02$; see Table 3$)$.

Among demented women with DS, age at menopause was significantly correlated with age at onset of $\mathrm{AD}$ (Pearson $r=0.54, p=0.003$; Fig 2). Linear regression analysis indicated that age at onset of $\mathrm{AD}$ increased by approximately half a year for each yearly increase in age at menopause $(\beta=0.53, p=0.003)$.

\section{Discussion}

Evidence to support the hypothesis that higher concentrations of endogenous estrogens may prevent cognitive decline and delay onset of AD has been inconsistent. In one study, healthy nondemented women older than 65

Table 2. Rate Ratio for Dementia by Age at Menopause in Women with Down Syndrome

\begin{tabular}{|c|c|c|c|c|}
\hline $\begin{array}{l}\text { Menopause } \\
\text { Group }\end{array}$ & $\mathrm{N}$ & Demented & $\begin{array}{l}\text { Rate } \\
\text { Ratio }^{a}\end{array}$ & $95 \% \mathrm{CI}$ \\
\hline $\begin{array}{l}\text { Age at menopause } \\
\leq 46 \mathrm{yr}\end{array}$ & 65 & 18 & 2.7 & $1.2-5.9^{\mathrm{b}}$ \\
\hline $\begin{array}{l}\text { Age at menopause } \\
\quad>46 \mathrm{yr}\end{array}$ & 46 & 12 & 1.0 & Reference \\
\hline
\end{tabular}

${ }^{a}$ Cox proportional hazards model, adjusting for age, level of mental retardation, body mass index, and history of hypothyroidism or depression.

${ }_{p}=0.016$

$\mathrm{CI}=$ confidence interval. 
Table 3. Hormone Levels by Dementia Status in Postmenopausal Women with Down Syndrome

\begin{tabular}{lcc}
\hline & $\begin{array}{c}\text { Nondemented, } \\
\mathrm{N}=69 \\
(\text { mean } \pm \mathrm{SE})\end{array}$ & $\begin{array}{c}\text { Demented, } \\
\mathrm{N}=24 \\
(\mathrm{mean} \pm \mathrm{SE})\end{array}$ \\
Hormone $^{\mathrm{a}}$ & $35.8(4.8)$ & $45.6(8.2)$ \\
$\begin{array}{l}\text { Total estradiol }\left(\mathrm{E}_{2}\right) \text { level } \\
(\mathrm{pg} / \mathrm{ml})\end{array}$ & & \\
$\begin{array}{l}\text { Estrone }\left(\mathrm{E}_{1}\right) \text { level }(\mathrm{pg} / \mathrm{ml}) \\
\text { Progesterone level }(\mathrm{ng} / \mathrm{ml})\end{array}$ & $31.1(3.9)$ & $42.0(6.5)$ \\
FSH level $(\mathrm{mIU} / \mathrm{ml})$ & $49.2(3.4)$ & $48.6(5.9)$ \\
SHBG level $(\mathrm{nmol} / \mathrm{L})$ & $56.5(6.4)$ & $86.5(10.9)^{\mathrm{b}}$ \\
DHEAS level $(\mu \mathrm{g} / \mathrm{dl})$ & $91.8(8.2)$ & $79.6(14.0)$ \\
\hline
\end{tabular}

${ }^{a}$ Multivariate analysis of covariance, adjusting for age, level of mental retardation, and body mass index.

${ }^{\mathrm{b}} p=0.02$.

$\mathrm{SE}=$ standard error; $\mathrm{FSH}=$ follicle-stimulating hormone; $\mathrm{SHBG}=$ sex hormone binding globulin; DHEAS = dehydroepiandrosterone sulfate.

years of age with high serum concentrations of nonprotein-bound and bioavailable estradiol were less likely to develop cognitive impairment than women with low serum estradiol concentrations. ${ }^{24}$ Two studies reported lower serum estradiol levels in patients with $\mathrm{AD}$ than in age-matched controls. ${ }^{25,26}$ However, other studies have found no relation of serum estrogen levels to cognitive function. ${ }^{22}$ Our results are consistent with the hypothesis that reductions in estrogens after menopause can contribute to the cascade of pathological processes leading to $\mathrm{AD}$ and accelerate the development of $\mathrm{AD}$ in women at high risk for $\mathrm{AD}$. We found that earlier age at menopause was associated with earlier age at onset of $A D$, and the relation of age at menopause to onset of AD did not change after accounting for level of mental retardation, BMI, and history of hypothyroidism or depression. Both

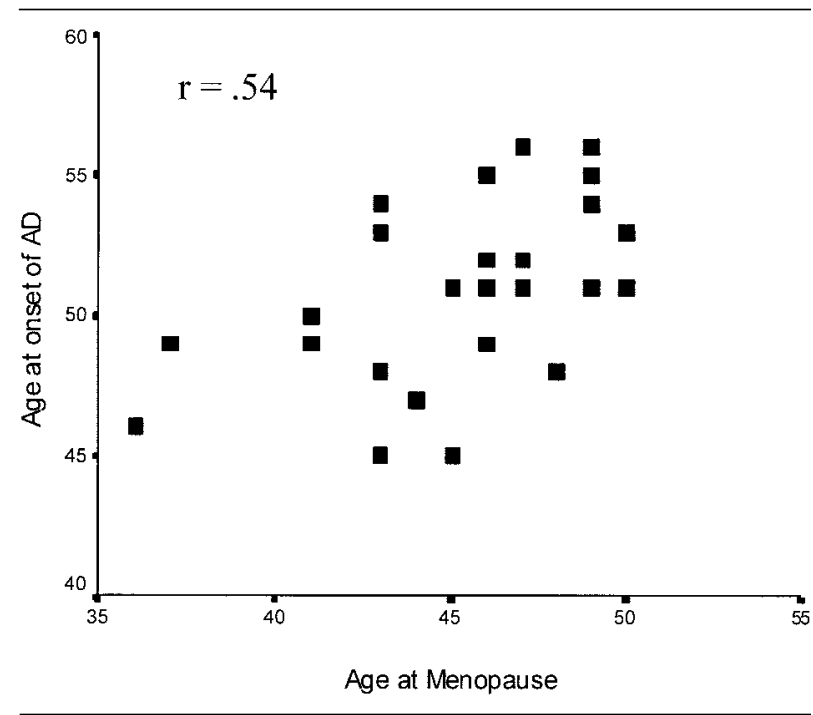

Fig 2. Age at onset of Alzheimer's disease (AD) by age at menopause in demented women with Down's syndrome. the presence of an ApoE $\varepsilon 4$ allele and a history of hypothyroidism were independent risk factors for $\mathrm{AD}$ but did not modify the association between age at menopause and age at onset of $\mathrm{AD}$. The median age at onset of $\mathrm{AD}$ was approximately 4 years earlier in those with early onset compared with those with late onset of menopause. Levels of SHBG were significantly higher in demented than in nondemented women. SHBG binds strongly and specifically to estradiol, reducing its ability to bind to receptors and initiate responses. The high SHBG levels in demented women suggest that bioavailable or free estradiol levels, the components of serum estradiol available to exert biological activity, may be lower in demented than in nondemented women and are associated with $\mathrm{AD}$. These findings are consistent with studies showing a neuroprotective effect for estrogen and point to disturbances in SHBG production or regulation, leading to reduced bioavailable estradiol, in patients with $\mathrm{AD}$.

This work was supported by a grant from the Alzheimer's Association (RG3-96-077, N.S.), by Federal grants (AG14673, N.S.; HD35897, W.S.; HD37425, W.Z.; P50AG08702, R.M.), and by funds provided by New York State though its Office of Mental Retardation and Developmental Disabilities.

We thank Drs W. Zigman, D. Devenny, E. Jenkins, and L.-L. Ye for assistance in assessment of participants. We also thank all the study participants, their families, and the state and voluntary agencies for their contribution to the conduct of this study.

\section{References}

1. Toran-Allerand CD, Miranda RC, Bentham WD, et al. Estrogen receptors colocalize with low-affinity nerve growth factor receptors in cholinergic neurons of the basal forebrain. Proc Natl Acad Sci USA 1992;89:4668-4672.

2. Goodman Y, Bruce AJ, Cheng B, Mattson MP. Estrogens attenuate and corticosterone exacerbates excitotoxicity, oxidative injury, and amyloid beta-peptide toxicity in hippocampal neurons. J Neurochem 1996;66:1836-1844.

3. Luine VN. Estradiol increases choline acetyltransferase activity in specific basic forebrain nuclei and projection areas of female rats. Exp Neurol 1985;89:484-490.

4. Behl C, Widmann M, Trapp T, Holsboer F. 17-beta estradiol protects neurons from oxidative stress-induced cell death in vitro. Biochem Biophys Res Commun 1995;216:473-482.

5. Jaffe AB, Toran-Allerand CD, Greengard P, Gandy SE. Estrogen regulates metabolism of Alzheimer amyloid beta precursor protein. J Biol Chem 1994;269:13065-13068.

6. Xu H, Gouras GK, Greenfield JP, et al. Estrogen reduces neuronal generation of Alzheimer beta-amyloid peptides. Nat Med 1998;4:447-451.

7. Greenfield JP, Leung LW, Cai D, et al. Estrogen lowers Alzheimer $\beta$-amyloid generation by stimulating trans-golgi network vesicle biogenesis. J Biol Chem 2002;277:12128-12136.

8. Petanceska SS, Nagy V, Frail D, Gandy S. Ovariectomy and 17 beta-estradiol modulate the levels of Alzheimer's amyloid beta peptides in brain. Neurology 2000;54:2212-2217.

9. Zheng $\mathrm{H}, \mathrm{Xu} \mathrm{K}$, Uljon $\mathrm{SN}$, et al. Modulation of $\mathrm{A} \beta$ peptides by estrogen in mouse models. Neurochemistry 2002;80:191-196.

10. Kampen DL, Sherwin BB. Estrogen use and verbal memory in healthy postmenopausal women. Obstet Gynecol 1994;83: 979-983. 
11. Phillips SM, Sherwin BB. Effects of estrogen on memory function in surgically menopausal women. Psychoneuroendocrinology 1992;17:485-495.

12. Tang MX, Jacobs D, Stern Y, et al. Effect of oestrogen during menopause on risk and age at onset of Alzheimer's disease. Lancet 1996;348:429-432.

13. Kawas C, Resnick S, Morrison A, et al. A prospective study of estrogen replacement therapy and the risk of developing Alzheimer's disease: the Baltimore Longitudinal Study of Aging. Neurology 1997; 48:1517-1521.

14. Jacobs DM, Tang MX, Stern Y, et al. Cognitive function in nondemented older women who took estrogen after menopause. Neurology 1998;50:368-373.

15. Yaffe K, Haan M, Byers A, et al. Estrogen use, ApoE, and cognitive decline: evidence of gene-environment interaction. Neurology 2000;54:1949-1954.

16. Paganini-Hill A, Henderson VW. Estrogen replacement therapy and risk of Alzheimer disease. Arch Intern Med 1996;156: 2213-2217.

17. Waring SC, Rocca WA, Petersen RC, et al. Postmenopausal estrogen replacement therapy and risk of $\mathrm{AD}$ : a populationbased study. Neurology 1999;52:965-970.

18. Barrett-Connor E, Kritz-Silverstein D. Estrogen replacement therapy and cognitive function in older women. JAMA 1993; 269:2637-2626.

19. Matthews K, Cauley J, Yaffe K, Zmuda JM. Estrogen replacement therapy and cognitive decline in older community women. J Am Geriatr Soc 1999;47:518-523.

20. Brenner DE, Kukull WA, Stergachis A, et al. Postmenopausal estrogen replacement therapy and the risk of Alzheimer's disease: a population-based case-control study. Am J Epidemiol 1994; 140:262-267.

21. Mayeux R. Can estrogen or selective estrogen-receptor modulators preserve cognitive function in elderly women? N Eng J Med 2001;344:1242-1244.

22. Barrett-Connor E, Goodman-Gruen D. Cognitive function and endogenous sex hormones in older women. J Am Geriatr Soc 1999;47:1289-1293.

23. Yaffe K, Grady D, Pressman A, Cummings S. Serum estrogen levels, cognitive performance, and risk of cognitive decline in older community women. J Am Geriatr Soc 1998;46:816-882.

24. Yaffe K, Lui LY, Grady D, et al. Cognitive decline in women in relation to non-protein-bound oestradiol concentrations. Lancet 2000;356:708-712.

25. Manly JJ, Merchant CA, Jacobs DM, et al. Endogenous estrogen levels and Alzheimer's disease among postmenopausal women. Neurology 2000;54:833-837.

26. Senanarong V, Vannasaeng S, Poungvarin N, et al. Enodgenous estradiol in elderly individuals: cognitive and noncognitive associations. Arch Neurol 2002;59:385-389.

27. Geerlings MI, Ruitenberg A, Witteman JC, et al. Reproductive period and risk of dementia in postmenopausal women. JAMA 2001;285:1475-1481.

28. Treolar AE. Menstrual cyclicity and the pre-menopause. Maturitas 1981;3:249-264.

29. Brambilla DJ, McKinlay SM, Johannes CB. Defining the perimenopause for application in epidemiologic investigations. Am J Epidemiol 1994;15:1091-1095.

30. Mann DM. The pathological association between Down's syndrome and Alzheimer disease. Mech Ageing Dev 1988;43:99-136.

31. Goldgaber D, Lerman MI, McBride WO, et al. Isolation, characterization, and chromosomal localization of human brain cDNA clones coding for the precursor of the amyloid of brain in Alzheimer's disease, Down's syndrome and aging. J Neural Transm Suppl 1987;24:23-28.
32. Rumble B, Retallack R, Hillbach C, et al. Amyloid A4 protein and its precursor in Down's syndrome and Alzheimer's disease. N Eng J Med 1989;320:1446-1452.

33. Schupf N, Zigman W, Kapell D, et al. Early menopause in women with Down's syndrome. J Intellect Disabil Res 1997;41:264-267.

34. Lai F, Kammann E, Rebeck GW, et al. ApoE genotype and gender effects on Alzheimer disease in 100 adults with Down's syndrome. Neurology 1999;53:331-336.

35. Cosgrave MP, Tyrrell J, McCarron M, et al. Age at onset of dementia and age of menopause in women with Down's syndrome. J Intellect Disabil Res 1999;43:461-465.

36. Corder EH, Saunders AM, Strittmatter WJ, et al. Gene dose of apolipoprotein E type 4 allele and the risk of Alzheimer's disease in late onset families. Science 1993;261:921-923.

37. Mayeux R, Stern Y, Ottman R, et al. The apolipoprotein epsilon 4 allele in patients with Alzheimer's disease. Ann Neurol 1993;34:752-754.

38. Schupf N, Kapell D, Lee JH, et al. Onset of dementia is associated with apolipoprotein E epsilon 4 in Down's syndrome. Ann Neurol 1996;40:799-801.

39. Haxby JV. Neuropsychological evaluation of adults with Down's syndrome: patterns of selective impairment in nondemented old adults. J Ment Defic Res 1989;33:193-210.

40. Wisniewski KE, Hill AL. Clinical aspects of dementia in mental retardation and developmental disabilities. In Wisniewski $\mathrm{H}$, Janicki $M$, editors. Aging and mental retardation. Baltimore, MD: Brookes, 1985:195-210.

41. Buschke H. Selective reminding for analysis of memory and learning. J Verbal Learn Verbal Behav 1972;12:543-550.

42. Dunn LM, Dunn LM. Peabody Picture Vocabulary Test-Revised. Circle Pines, MN: American Guidance Service, 1981.

43. McCarthy D. Scales of Children's Abilities. San Antonio, TX Psychological Corporation, 1972.

44. Beery KE, Bukenia NA. Developmental Test of Visual-Motor Integration. Cleveland, OH: Modern Curriculum Press, 1989.

45. Wechsler D. Wechsler Intelligence Scale for Children-Revised. New York: Psychological Corporation, 1974.

46. Albert M, Cohen C. The Test for Severe Impairment: an instrument for the assessment of patients with severe cognitive dysfunction. J Am Geriatr Soc 1992;40:449-453.

47. Nihira K, Foster R, Shellhaas M, Leland H. AAMD Adaptive Behavior Scale. Washington, DC: American Association on Mental Deficiency, 1974

48. Evenhuis HM, Kengen MMF, Eurlings HAL. Dementia Questionnaire for Mentally Retarded Persons. Zwanerdam, The Netherlands: Hooge Burch Institute for Mentally Retarded People, 1990.

49. Reiss $S$. Handbook of challenging behavior: mental health aspects of mental retardation. Worthington, OH: IDS Publishing, 1994

50. Burt DB, Aylward EH. Test battery for the diagnosis of dementia in individuals with intellectual disability. Working Group for the Establishment of Criteria for the Diagnosis of Dementia in Individuals with Intellectual Disability. J Intellect Disabil Res 2000;44:175-180.

51. WHO. World Health Organization International Classification of Diseases. Geneva: World Health Organization, 1980.

52. Stanford JL, Hartge P, Brinton LA, et al. Factors influencing the age at natural menopause. J Chronic Dis 1987;40:995-1002.

53. Cauley JA, Gutai JP, Kuller LH, et al. The epidemiology of serum sex hormones in postmenopausal women. Am J Epidemiol 1989;129:1120-1131.

54. Cox DR, Oakes D. Analysis of survival data. New York: Chapman and Hall, 1984.

55. SPSS. SPSS 11.0 for Windows. Chicago, IL: SPSS, 2001. 